\title{
DINÂMICA MIGRATÓRIA RECENTE NA RM DE CAMPINAS: ANÁLISE DOS FATORES ASSOCIADOS ${ }^{1}$
}

\author{
RECENT MIGRATION DYNAMICS IN THE RM OF CAMPINAS: ANALYSIS \\ OF ASSOCIATED FACTORS
}

Ednelson Mariano Dota ${ }^{2}$

\begin{abstract}
RESUMO
Os resultados em termos de organização socioespacial das grandes cidades tornam-se cada vez mais complexos de se analisar: novas variáveis começam a se destacar e a sociedade fluída do século XXI tem nos fluxos de população a possibilidade de novas escolhas locacionais, que impactam a forma e o direcionamento da expansão urbana. As regiões metropolitanas, neste sentido, são lócus dos movimentos de população, que representam fator imponderável com causas e motivações das mais diversas ordens, e que deve ser mais bem entendida para que se possa melhor compreender seus resultados socioespaciais. O presente trabalho analisa a dinâmica migratória recente da Região Metropolitana de Campinas a partir dos fatores associados, utilizando-se para isso dados do Censo Demográfico de 2010 e dois modelos de regressão logística binária para migrantes e "não-migrantes", considerando as características sociodemográficas e as variáveis do contexto social. Observa-se, a partir de tal metodologia, migrantes com características bem definidas e uma estreita relação com as dinâmicas habitacionais e do mercado de trabalho, a partir da concentração espacial das oportunidades em âmbito regional.
\end{abstract}

PALAVRAS-CHAVE: Migração. Mobilidade residencial. Trabalho. Residência. Região

Metropolitana de Campinas.

\begin{abstract}
The results in terms of socio-spatial organization of large cities become increasingly complex to analyze: new variables begin to stand out and the fluid society of XXI century has on population flows the possibility of new locational choices that impact the way and the direction of urban growth. The metropolitan areas in this regard are locus of population movements, representing imponderable factor with causes and motivations of the different orders, and that should be better analyzed so that we can better understand their socio-spatial results. This paper analyzes the recent migration dynamics in the metropolitan region of Campinas from the associated factors, using the Demographic Census 2010 and two models of binary logistic regression for migrants and "non-migrants", considering the sociodemographic characteristics and the variables of the social context. As result, is observed migrants with distinctive characteristics and a close relationship with the housing and labor market dynamics and relation with the spatial concentration of opportunities at the regional level.
\end{abstract}

\footnotetext{
${ }^{1}$ Uma primeira versão deste trabalho foi apresentada no VI Congresso da Associação Latino-americana de População, realizado em Lima-Peru em 2014.

${ }^{2}$ Geógrafo, Doutor em Demografia, Professor do Departamento de Geografia da Universidade Federal do Espírito Santo. Telefone: 27 3145-5338. E-mail: ednelsondota@gmail.com.
} 
KEYWORDS: Migration. Residencial Mobility. Work. Residência. Metropolitan Region of Campinas.

\section{INTRODUÇÃO}

A mudança estrutural que a sociedade tem observado nas últimas décadas, nos âmbitos político, econômico e social, tem suscitado inúmeros desafios às ciências humanas, em busca de compreender o significado destas em termos objetivos. A reprodução social, que tem como principal elemento o trabalho - meio pelo qual os indivíduos e famílias angariam recursos para adquirir produtos e serviços básicos à sobrevivência - tem passado por extensivas mudanças, fruto da passagem do fordismo para a “acumulação flexível”, nos termos de Harvey (1992) ou, em outros termos, da reestruturação produtiva observada de diversas maneiras em cada setor da economia (SANTOS, 1996; SASSEN, 1998).

O acesso aos serviços, entretanto, sejam aqueles ligados à infraestrutura básica ou outros mais especializados estão mediados não apenas pela renda, mas também pelo local de moradia, o que torna a localização uma das dimensões a serem consideradas nos estudos de condições de vida da população. O local onde as pessoas residem também influencia em relação ao maior ou menor acesso às oportunidades de trabalho, que estará mediada pelas características sociodemográficas dos indivíduos, que potencializam ou limitam esse acesso (DOTA, 2015).

Se a localização em que se reside é importante, o fato da população mover-se ou, mais especificamente, os grupos sociais (SINGER, 1976) - relativiza e reafirma o papel da localização (MARANDOLA JR., 2008): relativiza a partir da possibilidade da população se mover, mas também o reafirma já que o local em que se reside independe das escolhas individuais, é resultado de um conjunto de fatores, econômicos e sociais, objetivos e subjetivos.

Neste contexto, em relação às discussões sobre as formas como a população se mobiliza e se redistribui, vários tipos de movimentos têm sido observados, estando cada um deles associados a outros processos, fenômenos e formas nas áreas urbanas (OJIMA, 2007). Cabe, por exemplo, diferenciar a migração, a mobilidade residencial e a mobilidade pendular: apesar da forte relação existente entre as três, apresentam especificidades que culminam em processos e fatores distintos em relação a sua 
existência e, consequentemente, apresentam resultados específicos para cada grupo de população segundo as características sociodemográficas predominantes.

A mobilidade pendular se refere aos movimentos casa-trabalho e/ou casa-escola, mais próximos do cotidiano dos indivíduos e com grande impacto na infraestrutura de mobilidade das cidades (OJIMA; MARANDOLA JR, 2013; FREY; DOTA, 2013; CUNHA et al., 2013). A mobilidade residencial, por outro lado, se refere à mudança de residência no contexto das aglomerações e com municípios fortemente integrados, onde são mantidos fatores relevantes para a reprodução social, como o trabalho, as redes de contato etc. (DOTA, 2015; SOBRINO, 2010). A migração, por sua vez, se refere aos movimentos de mais longa distância, com significa mudança no espaço de vida dos migrantes.

O papel destes movimentos como resposta aos fatores estruturantes da sociedade, mas também como fator que estrutura as localidades de ocorrência fica evidente nas áreas mais adensadas, já que nestas os movimentos mais curtos, como a mobilidade residencial, apresenta maior importância relativa. Por outro lado, os contextos destas aglomerações são específicos, e o maior ou menor volume de migrantes de longa distância funciona, muitas vezes, como "motor" para a movimentação interna estando, portanto, interrelacionados.

Outro aspecto a ser ressaltado é que o próprio fenômeno migratório tem passado por modificações relevantes, visto que as características relacionadas aos incentivos e constrangimentos observadas décadas atrás, no auge dos fluxos de longa distância, hoje se apresentam distintos, assim como os próprios fluxos, em relação às origens, destinos e volumes observados (CUNHA; BAENINGER, 2007; BRITO, 2009; RODRIGUES, 2011).

A intensa circulação tem resultado em constante reestruturação na dimensão regional, criando condições e impondo limites à mobilidade: ao mesmo tempo em que os fluxos cotidianos aumentam, aqueles de mobilidade residencial tendem a se modificar, culminando numa reorganização espacial da população com características locacionais bem marcadas, modificando o aproveitamento das infraestruturas existentes (RODRIGUES; BUSSO, 2009) e aprofundando as desigualdades territoriais e sociais (DOTA, 2015).

Essas desigualdades são reforçadas pela valorização diferencial das localidades (VILLAÇA, 1993), visto que o acesso regulado pelo mercado impõe a compra ou locação do domicílio. Sendo os incentivos e constrangimentos distintos conforme a Serv. Soc. \& Saúde, Campinas, SP v.14, n. 2 (20), p. 157-172, jul./dez. 2015 ISSN 1676-6806 
modalidade migratória, distintas também são as características dos indivíduos que participam destas modalidades e, consequentemente, a redistribuição espacial da população tende a homogeneização socioeconômica das áreas que recebem ou cedem população. Apesar dos resultados pontuais, os fatores causais destes movimentos devem ser compreendidos num plano mais amplo, já que estão atrelados às modificações estruturais da sociedade.

Dentro deste contexto, o presente trabalho objetiva analisar os fatores associados à migração, mais especificamente aqueles que diferenciam os migrantes recentes do restante da população residente, em 2010, na Região Metropolitana de Campinas. Busca-se aprofundar o entendimento sobre o papel das características sociodemográficas e do contexto territorial para os movimentos, de forma a compreender a relação de mútua influencia entre a mobilidade espacial da população e a produção do espaço urbano nas aglomerações urbanas, cujos resultados impactam diretamente as condições de vida, assim como na própria organização socioespacial destas áreas.

\section{O CONTEXTO DA RM DE CAMPINAS}

A RM de Campinas, composta por 20 municípios, tem representado desde a década de 70 um importante polo de atração populacional do Estado de São Paulo, fato que culminou num grande crescimento nos últimos 40 anos, principalmente pelo saldo migratório positivo observado desde então. A Tabela 1 apresenta o período mais recente, em que a região, ainda apresentando crescimento razoável, passa a uma dinâmica semelhante a todo o país, de redução gradativa do crescimento, fruto principalmente da redução das taxas de fecundidade: neste caso, o papel da migração no incremento populacional manteve-se relevante, visto que, entre 2000 e 2010, já com redução da importância, metade do incremento regional foi resultado da migração (DOTA; FREY, 2012; CUNHA et al., 2013). 
Tabela 1. População residente e taxa de crescimento. Municípios da RMC. 1980 2010.

\begin{tabular}{l|ccc|cc}
\hline \multirow{2}{*}{\multicolumn{1}{c|}{ Município }} & \multicolumn{3}{c|}{ População residente } & \multicolumn{2}{c}{$\begin{array}{c}\text { Taxa de crescimento (\% } \\
\text { a.a.) }\end{array}$} \\
\cline { 2 - 6 } & $\mathbf{1 9 9 1}$ & $\mathbf{2 0 0 0}$ & $\mathbf{2 0 1 0}$ & $\mathbf{1 9 9 1 - 2 0 0 0}$ & $\mathbf{2 0 0 0 - 2 0 1 0}$ \\
\hline RM Campinas & $\mathbf{1 . 8 6 0 . 9 8 7}$ & $\mathbf{2 . 3 4 2 . 8 8 1}$ & $\mathbf{2 . 8 0 8 . 8 8 9}$ & $\mathbf{2 . 5 9}$ & $\mathbf{1 . 8 2}$ \\
Americana & 153.273 & 182.300 & 210.638 & 1.95 & 1.44 \\
Artur Nogueira & 27.811 & 32.965 & 44.177 & 1.91 & 2.95 \\
Campinas & 843.516 & 968.160 & 1.080 .113 & 1.54 & 1.09 \\
Cosmópolis & 36.421 & 44.250 & 58.827 & 2.19 & 2.86 \\
Engenheiro Coelho & $*$ & 10.000 & 15.721 & $*$ & 4.59 \\
Holambra & $*$ & 7.195 & 11.299 & $*$ & 4.58 \\
Hortolândia & $*$ & 151.697 & 192.692 & $*$ & 2.40 \\
Indaiatuba & 99.949 & 146.530 & 201.619 & 4.34 & 3.22 \\
Itatiba & 61.236 & 80.987 & 101.471 & 3.15 & 2.26 \\
Jaguariúna & 24.819 & 29.533 & 44.311 & 1.95 & 4.11 \\
Monte Mor & 25.291 & 37.207 & 48.949 & 4.38 & 2.76 \\
Morungaba & 8.174 & 9.893 & 11.752 & 2.14 & 1.93 \\
Nova Odessa & 33.876 & 41.987 & 51.242 & 2.41 & 2.00 \\
Paulínia & 36.298 & 51.163 & 82.146 & 3.89 & 4.81 \\
Pedreira & 27.653 & 35.141 & 41.558 & 2.70 & 1.68 \\
Santa Bárbara d'Oeste & 143.945 & 169.818 & 180.009 & 1.85 & 0.58 \\
Santo Antonio de Posse & 14.272 & 18.074 & 20.650 & 2.66 & 1.33 \\
Sumaré & 223.553 & 196.099 & 241.311 & -1.45 & 2.08 \\
Valinhos & 67.545 & 82.817 & 106.793 & 2.29 & 2.55 \\
Vinhedo & 33.355 & 47.065 & 63.611 & 3.90 & 3.03 \\
\hline \hline
\end{tabular}

* Municípios emancipados em 1993.

Fonte: IBGE. Censo Demográfico de 1991, 2000 e 2010.

Pode-se observar, neste sentido, que apesar de o crescimento regional ter diminuído na última década, entre os municípios os números apresentaram variação, sendo que alguns deles chegaram a apresentaram aumento do crescimento médio anual, casos de Artur Nogueira, Cosmópolis, Jaguariúna, Paulínia e Valinhos.

A atratividade exercida por esta região tem, na verdade, um conjunto de explicações: a desconcentração econômica a partir da capital iniciada no final da década de 60, num período de grande êxodo rural, beneficiou Campinas e os municípios do entorno, culminando num importante destino para aqueles que buscavam uma área não apenas urbana, mas também com empregos nas indústrias que estavam se instalando na região (BAENINGER, 1992; 1999). 
Mais recentemente, com a região consolidada, é o conjunto dos fluxos, internos e externos, que impactam os diferenciais de crescimento dos municípios, que acabam por apresentar dinâmica relacionada ao crescimento e expansão muitas vezes diferenciada entre si. Para Cunha et al. (2006), preço e acessibilidade são dois fatores fundamentais na escolha pelo local de residência, e esta escolha, que não é aleatória, culmina em resultados socioespacial que influenciam e conformam outros movimentos, numa relação dialética que marca a (re)produção do espaço urbano regional (DOTA, 2012; 2015).

O Mapa 1 apresenta os municípios que mais concentraram migrantes entre 2005 e 2010. Pode-se verificar que Campinas continua sendo o principal receptor, seguido pelos municípios do entorno imediato. Tal concentração se explica devido ao também concentrado mercado de trabalho regional, que oferece maior volume de oportunidades em Campinas e nos municípios do entorno imediato.

Mapa 1. Distribuição dos migrantes recentes segundo o município de residência. RMC, 2010

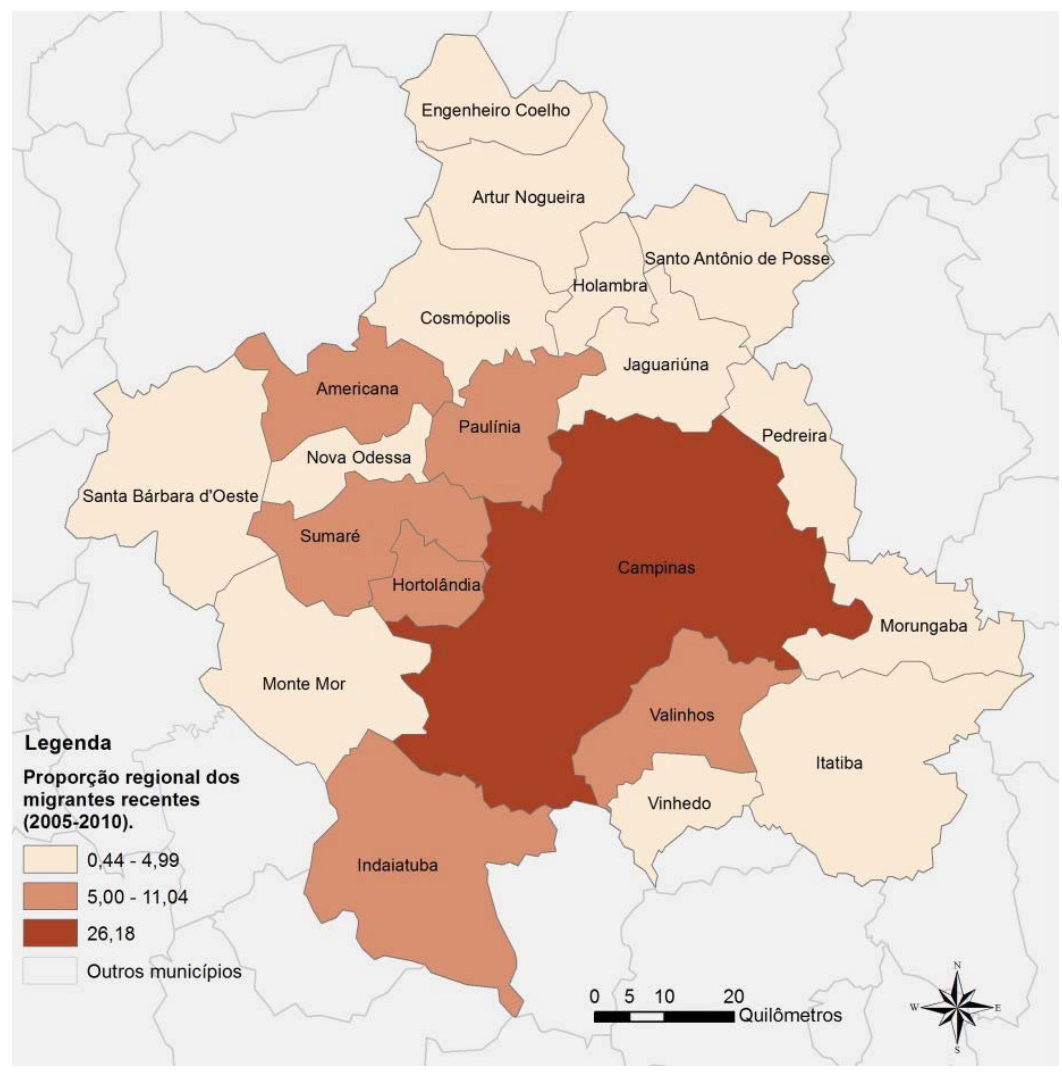

Fonte: Dota (2015) 
Com essas especificidades e uma ampla gama de possibilidades, torna-se cada vez mais complexo afirmar as causas e motivos que levam à migração e a mobilidade residencial na RM de Campinas: uma análise dos fatores associados a esses movimentos, de uma forma mais ampla, é o que se busca para avançar no entendimento destas e, com isso, compreender melhor suas características e resultados.

\section{DIFERENCIAIS ANALÍTICOS E METODOLÓGICOS ENTRE O MIGRANTE E O NÃO-MIGRANTE}

Para alcançar os objetivos propostos, o presente trabalho utiliza-se dos dados do Censo Demográfico de 2010, a partir de questões relacionadas à migração, às características sociodemográficas dos habitantes e o respectivo contexto social em que estão inseridos.

O recorte espacial são os vinte municípios componentes da RM de Campinas, e a população residente nestes será dividida em dois grupos: "migrantes recente” e “restante da população”. A variável utilizada para diferenciar migrantes recentes e o restante da população se baseou na questão “município de residência anterior”, visto que possibilita selecionar enquanto grupo alvo os indivíduos com até 10 anos de residência nos municípios da região ${ }^{3}$. Tal recorte possibilita analisar quais são as especificidades dos migrantes com até 10 anos nos municípios em relação ao restante da população, tanto em relação às características sociodemográficas quanto o contexto em que se encontram na região.

Em relação a origem desses migrantes, não foi realizado recorte algum, visto que se quer analisar as características destes em relação ao restante da população. Neste sentido, está se considerando no grupo dos migrantes tanto aqueles que realizaram movimento de longa quanto de curta distância, não diferenciando, portanto, a migração da mobilidade residencial.

Considerando a população total da região, 19,8\% se enquadrariam como migrante, passando a 23,1\% quando selecionados apenas os maiores de quinze anos responsáveis pelo domicílio, garantindo assim a possibilidade de incluir questões como

\footnotetext{
${ }^{3}$ Cabe salientar alguns aspectos da presente abordagem: o que se chama de migrante neste trabalho, na verdade, se refere a parcela dos migrantes com tempo de residência de até 10 anos nos municípios da região, escolha metodológica do presente trabalho. Neste sentido, dentro do grupo "restante da população", na verdade, encontram-se além de não-migrantes aqueles migrantes com tempo de residência maior do que 10 anos nos municípios da região e que, portanto, não fazem parte do grupo de interesse.

Serv. Soc. \& Saúde, Campinas, SP v.14, n. 2 (20), p. 157-172, jul./dez. 2015 ISSN 1676-6806
} 
trabalho, renda e escolaridade no modelo, além de variáveis domiciliares, que são representativas do contexto social dos indivíduos ${ }^{4}$.

Para eleger as variáveis com probabilidade de significância (valor de p), foram calculados modelos univariados entre a variável dependente e cada uma das independentes, sendo elegíveis aquelas com valor inferior a 0,20. Esse procedimento teve o objetivo de reduzir o risco de exclusão de variáveis importantes, assim como de inclusão de outras que poderiam gerar confusão, utilizando-se assim critérios estatísticos para analisar variáveis tradicionalmente apontadas pela literatura.

As variáveis eleitas para gerar os modelos de regressão logística binária foram as seguintes: sexo (masculino ou feminino), faixa etária, incluída em grupos de idade (15 a 29, 30 a 44, 45 a 59 e 60 anos e mais); a escolaridade foi analisada a partir de grupos, considerando o nível de instrução dos indivíduos (sem instrução, ensino fundamental, ensino médio ou superior), e a situação conjugal diferenciou aqueles que vivem com cônjuge ou não, ou seja, sozinho ou unido. Em relação ao contexto social, foi utilizado o município de trabalho do indivíduo (mesmo de residência ou outro), posse ou não de veiculo automotor (carro ou moto) e a condição de ocupação do domicilio em que reside (próprio, alugado ou outro).

A Tabela 2 apresenta a proporção de migrantes e do restante da população em cada uma das variáveis elegidas para o modelo. Quanto ao sexo, percebe-se que os migrantes do sexo masculino tem maior representatividade no conjunto da população do que aqueles do sexo feminino, entretanto essa diferença não se destaca a ponto de rotular o movimento como mais específico de um ou outro sexo.

Em relação à idade, percebe-se a preponderância dos migrantes nas faixas altamente produtivas, reduzindo gradativamente a participação quanto maior o grupo etário considerado. Assim como para a idade, a escolaridade também apresenta resultado típico da seletividade migratória inerente destes movimentos: quanto maior a escolaridade, maior a proporção dos migrantes no conjunto da população.

O estado conjugal é outra variável relevante para as análises migratórias, visto que migrar sozinho ou com a família representam custos completamente distintos e, muitas vezes, esses inviabilizam o movimento. Neste caso, os migrantes sozinhos apresentam proporção ligeiramente superior em relação àqueles unidos.

\footnotetext{
${ }^{4}$ A escolha de trabalhar apenas com os responsáveis pelo domicílio explica-se pelo uso de variáveis domiciliares enquanto representativas do contexto social dos indivíduos Serv. Soc. \& Saúde, Campinas, SP v. 14, n. 2 (20), p. 157-172, jul./dez. 2015 ISSN 1676-6806
} 
As três últimas variáveis, que apresentam o local de trabalho, a condição de ocupação do domicílio e a posse de veículo, são aproximações do contexto social a que os indivíduos estão expostos: em relação ao local de trabalho, percebe-se relevante peso dos migrantes dentre aqueles que trabalham em municípios distintos daquele de residência, assim como em relação à condição de ocupação do domicílio, os migrantes tem grande peso dentre os que pagam aluguel, e baixa representatividade enquanto proprietário da residência. Quanto à posse de veículo, percebe-se um peso maior dos migrantes dentre aqueles que não detêm a posse.

Tabela 2. Distribuição percentual dos migrantes e do restante da população segundo variáveis independentes. RM de Campinas. 2010.

\begin{tabular}{|c|c|c|c|}
\hline Variáveis & Categorias & $\begin{array}{c}\text { Restante da } \\
\text { população }\end{array}$ & Migrante \\
\hline \multirow{2}{*}{ Sexo } & Masculino & 76.3 & 23.7 \\
\hline & Feminino & 78.4 & 21.6 \\
\hline \multirow{4}{*}{ Faixa Etária } & 15 а 29 & 58.3 & 41.7 \\
\hline & 30 a 44 & 74.6 & 25.4 \\
\hline & 45 a 59 & 85.8 & 14.2 \\
\hline & 60 e mais & 90.5 & 9.5 \\
\hline \multirow{4}{*}{ Escolaridade } & Sem instrução & 80.2 & 19.8 \\
\hline & Fundamental & 78.7 & 21.3 \\
\hline & Médio & 75.9 & 24.1 \\
\hline & Superior & 69.9 & 30.1 \\
\hline \multirow{2}{*}{$\begin{array}{l}\text { Estado } \\
\text { conjugal }\end{array}$} & Sozinho & 75.7 & 24.3 \\
\hline & Unido & 77.3 & 22.7 \\
\hline \multirow{2}{*}{$\begin{array}{l}\text { Local de } \\
\text { trabalho }\end{array}$} & $\begin{array}{r}\text { No município de } \\
\text { residência }\end{array}$ & 80.0 & 20.0 \\
\hline & Em outro município & 67.3 & 32.7 \\
\hline \multirow{3}{*}{$\begin{array}{l}\text { Condição de } \\
\text { ocupação }\end{array}$} & Próprio & 85.4 & 14.6 \\
\hline & Alugado & 55.2 & 44.8 \\
\hline & Outros & 78.6 & 21.4 \\
\hline \multirow{2}{*}{$\begin{array}{l}\text { Posse de } \\
\text { veículo }\end{array}$} & Não & 71.6 & 28.4 \\
\hline & Sim & 78.6 & 23.1 \\
\hline
\end{tabular}

Fonte: FIBGE. Censo Demográfico de 2010. Elaborada pelo autor.

A Tabela 3 apresenta as razões de chance em dois modelos ${ }^{5}$, sendo o primeiro apenas com as variáveis sociodemográficas e o segundo incluindo também aquelas do contexto social. Em relação ao primeiro modelo (Modelo 1), percebe-se maior chance

\footnotetext{
${ }^{5}$ Foram realizadas as análises de resíduos para os dois modelos, não encontrando nenhum problema em relação aos pressupostos para a qualidade de ambos.
}

Serv. Soc. \& Saúde, Campinas, SP v.14, n. 2 (20), p. 157-172, jul./dez. 2015 ISSN 1676-6806 
dos migrantes serem do sexo masculino, mais jovens, possuírem ensino superior e serem sozinhos. Chama atenção, em relação à escolaridade a menor propensão ao ensino fundamental e médio em relação àqueles sem instrução (16\% e 11\%, respectivamente), e a maior a chance ( $54 \%$ em relação aos sem instrução) de apresentarem ensino superior como escolaridade.

Tabela 3. Razão de chance para migrante segundo variáveis sociodemográficas e do contexto social. RM de Campinas, 2010.

\begin{tabular}{|c|c|c|c|c|c|}
\hline \multirow[b]{2}{*}{ Variáveis } & \multirow{2}{*}{ Categorias } & \multicolumn{2}{|c|}{ Modelo 1} & \multicolumn{2}{|c|}{ Modelo 2} \\
\hline & & $\begin{array}{c}\text { Razão de } \\
\text { chance }\end{array}$ & IC95\% & $\begin{array}{c}\text { Razão de } \\
\text { chance }\end{array}$ & IC95\% \\
\hline Sexo & $\begin{array}{l}\text { Masculino } \\
\text { Feminino }\end{array}$ & $\begin{array}{c}1 \\
0,774^{* * *} \\
\end{array}$ & $\begin{array}{c}- \\
0,733- \\
0,818 \\
\end{array}$ & $\begin{array}{c}1 \\
0,808^{* * *} \\
\end{array}$ & $\begin{array}{c}- \\
0,763- \\
0,857\end{array}$ \\
\hline Faixa Etária & $\begin{array}{r}15 \text { a } 29 \\
30 \text { a } 44 \\
45 \text { a } 59 \\
60 \text { e mais }\end{array}$ & $\begin{array}{c}1 \\
0,457^{* * *} \\
0,215^{* * *} \\
0,133^{* * *}\end{array}$ & $\begin{array}{c}- \\
0,432- \\
0,483 \\
0,201- \\
0,229 \\
0,118- \\
0,150\end{array}$ & $\begin{array}{c}1 \\
0,588^{* * *} \\
0,3298^{* * *} \\
0,234^{* * *}\end{array}$ & $\begin{array}{c}- \\
0,547- \\
0,616 \\
0,307- \\
0,353 \\
0,207- \\
0,265\end{array}$ \\
\hline Escolaridade & $\begin{array}{r}\text { Sem instrução } \\
\text { Fundamental } \\
\text { Médio } \\
\text { Superior }\end{array}$ & $\begin{array}{c}1 \\
0,840^{* * *} \\
0,893^{* * *} \\
1,549 * * *\end{array}$ & $\begin{array}{c}- \\
0,786- \\
0,899 \\
0,844- \\
0,945 \\
1,453- \\
1,650 \\
\end{array}$ & $\begin{array}{c}1 \\
0,850^{* * *} \\
0,949 \\
1,836^{* * *}\end{array}$ & $\begin{array}{c}- \\
0,792- \\
0,912 \\
0,893- \\
1,00 \\
1,711- \\
1,971 \\
\end{array}$ \\
\hline $\begin{array}{c}\text { Estado } \\
\text { conjugal }\end{array}$ & $\begin{array}{r}\text { Sozinho } \\
\text { Unido }\end{array}$ & $\begin{array}{c}1 \\
0,825^{* * *}\end{array}$ & $\begin{array}{c}- \\
0,780- \\
0,871\end{array}$ & $\begin{array}{c}1 \\
1,01\end{array}$ & $\begin{array}{c}- \\
0,952- \\
1,072\end{array}$ \\
\hline $\begin{array}{l}\text { Local de } \\
\text { trabalho }\end{array}$ & $\begin{array}{l}\text { No município de residência } \\
\text { Em outro município }\end{array}$ & & & $\begin{array}{c}1 \\
1,99 * * *\end{array}$ & $\begin{array}{c}- \\
1,893- \\
2,096\end{array}$ \\
\hline $\begin{array}{l}\text { Condição de } \\
\text { ocupação }\end{array}$ & $\begin{array}{r}\text { Próprio } \\
\text { Alugado } \\
\text { Outros } \\
\end{array}$ & & & $\begin{array}{c}1 \\
4,09^{* * *} \\
1,50^{* * *} \\
\end{array}$ & $\begin{array}{c}- \\
3,894- \\
4,312 \\
1,379- \\
1,631 \\
\end{array}$ \\
\hline $\begin{array}{c}\text { Posse de } \\
\text { veículo }\end{array}$ & $\begin{array}{l}\text { Não } \\
\text { Sim }\end{array}$ & & & $\begin{array}{c}1 \\
0,767 * * * \\
\end{array}$ & $\begin{array}{c}- \\
0,725- \\
0,811 \\
\end{array}$ \\
\hline
\end{tabular}

Significância: *** $\mathrm{p}<0,001 ;{ }^{* *} \mathrm{p}<0,01 ;{ }^{*} \mathrm{p}<0,05$

Fonte: FIBGE. Censo Demográfico de 2010. Elaborada pelo autor. 
Quanto ao segundo modelo (Modelo 2), no qual estão inclusas as variáveis do contexto social, percebe-se ligeira modificação nas razões de chance das variáveis sociodemográficas, mas os resultados não se modificam substancialmente. Destaca-se o ligeiro aumento da chance do sexo feminino em relação ao masculino, assim como a chance dos migrantes de maior idade, reduzindo a diferença apresentada em relação ao grupo de referência (15 a 29 anos).

Quanto à escolaridade, aqueles com ensino fundamental apresentaram menor chance (-20\%), enquanto a associação positiva com o ensino superior se fortaleceu, passando a uma chance $83 \%$ maior em relação aqueles sem instrução (grupo de referência).

As variáveis do contexto social mostraram forte associação: os migrantes apresentaram praticamente duas vezes mais chance de trabalharem em município distinto daquele de residência, assim como quatro vezes mais chance de residirem via aluguel ou 50\% mais chance de morar por outros meios distintos ${ }^{6}$ em relação a ser proprietário da residência (referência). Por fim, os migrantes apresentaram chance 24\% menor de possuírem veículo do que de não possuir.

\section{ALGUNS APONTAMENTOS A PARTIR DOS RESULTADOS}

Os resultados apresentados apontam para um fortalecimento do processo de seletividade migratória, que aparentemente tende a tornar-se mais restritivo quanto mais dinâmica, em termos sociais e econômicos, for a área de destino.

No caso da RM de Campinas, fatores com a maior associação com os migrantes com a idade mais jovem, a escolaridade mais alta e os “não-unidos” em relação aos unidos são apontamentos do custo do movimento e, portanto, essas características se associam pois possibilitam acesso ao mercado de trabalho mais facilmente (idade), maior renda (escolaridade) e menos custos ao migrar (por estar sozinho).

As variáveis representantes do contexto social apontam outros processos que são inerentes à organização de uma região metropolitana, como a interdependência e a complementariedade: trabalhar em município distinto daquele de residência torna-se cada vez mais frequente, tendo praticamente dobrado o volume entre 2000 e 2010 (CUNHA et al.,2013). A possibilidade de se fazer o movimento pendular, inclusive, tem impacto no próprio crescimento das aglomerações, visto que novas possibilidades de

\footnotetext{
${ }^{6}$ Domicílios de alguma forma cedidos ou em áreas de ocupação. Serv. Soc. \& Saúde, Campinas, SP v.14, n. 2 (20), p. 157-172, jul./dez. 2015 ISSN 1676-6806
} 
ocupação surgem - inclusive em maiores distâncias - quando são consideradas as possibilidades de locomoção cotidiana (FREY; DOTA, 2013).

Além disso, a menor propensão a ser proprietário da residência que ocupa é indicativo tanto do pouco tempo e conhecimento da localidade, que desfavorece o aproveitamento de oportunidades imobiliárias, como também da relativa flexibilidade inicial, que tende a se reduzir com a territorialização dos indivíduos - ao menos da parcela que se estabiliza -, que envolveria muitas vezes a união conjugal, a estabilização no trabalho e consequentemente a estabilização em relação à residência.

A posse de veículos, que se imaginou que tenderia a ser maior entre migrantes pela necessidade recorrente de mobilidade, na verdade apresentou resultado inverso, fato que deve estar relacionado à condição econômica com que estes chegam à região: mais do que recém-chegados, estão em busca de consolidação econômica e a posse de veículo, neste caso, pode ser um fator representativo das condições destes no momento da migração.

\section{CONSIDERAÇÕES FINAIS}

Os resultados aqui apresentados apontam para relevantes modificações na estrutura sociodemográfica da população residente na RM de Campinas, resultado de uma migração cada vez mais seletiva. Esta estrutura, que se modifica ao longo do tempo como resultado da transição demográfica, tem na migração o seu fator imponderável, com volumes e distribuição aleatória ao longo do tempo, mas com grande impacto no incremento populacional.

A migração recente na $\mathrm{RM}$ de Campinas, região que permanece recebendo volume considerável de migrantes, apresenta indivíduos com características cada vez mais específicas, resultado da seletividade migratória inerente aos fluxos a depender do seu destino. Neste sentido, o que se verifica é que a especialização das áreas, em termos sociais e econômicos, resulta também numa modificação do perfil do migrante que se dirige para estas, promovendo assim uma mudança estrutural nas características da população via migração.

O perfil dos migrantes e os resultados apresentados nos modelos indicam, entretanto, que apresentam condições de vida menos favorecidas em relação ao restante da população. Em conjunturas específicas, como crises econômicas e baixa nas oportunidades de trabalho tendem a expor esses migrantes à condições degradantes de 
vida, já que o contexto no momento de chegada ou nos primeiros anos após a instalação, como os dados apontam, em muito dependem da inserção produtiva para a estabilização.

O contexto em que os migrantes são inseridos na região, a partir do município a que se destinam é resultado de dinâmicas que extrapolam o âmbito do indivíduo, apresentando relação com a própria condição socioterritorial da região metropolitana, que promove constantemente trocas - resultado da imigração e emigração - que não necessariamente são de indivíduos com as mesmas características, e que ao longo do tempo culminam numa valorização diferenciada das várias partes da região.

Desta forma, outras análises, que incluam aqueles que emigraram, os migrantes com maior tempo de residência ou mesmo distinguindo entre outras modalidades mostram-se de grande relevância para efetivamente compreender quais são os resultados em termos sociais da migração recente, além de que tipo de conformação territorial em grande escala estará se construindo no Estado de São Paulo e no Brasil. Essa estruturação mais ampla, além de impactar novos fluxos, acarretará também em novos contextos de atenção aos resultados da migração por parte das políticas públicas nas distintas localidades.

Recebido em 13.07.2015 - Aprovado em 14.10.2015

\section{REFERÊNCIAS}

BAENINGER, R. A. Espaço e Tempo em Campinas: migrantes e a expansão do polo industrial paulista. Campinas. Dissertação (Mestrado). IFCH/UNICAMP, 1992.

BAENINGER, R. Região, metrópole e interior: espaços ganhadores e espaços perdedores nas migrações recentes no Brasil - 1980/1996, (tese de doutorado). Instituto de Filosofia e Ciências Humanas, Universidade Estadual de Campinas, 1999.

BRITO, F. As migrações internas no Brasil: um ensaio sobre os desafios teóricos recentes. Belo Horizonte: UFMG/Cedeplar, 2009.

CUNHA, J. M. P. da; JAKOB, A. A. E. ; JIMÉNEZ, M. A.; TRAD, I. L. Expansão Metropolitana, mobilidade espacial e segregação nos anos 90: o caso da RM de Campinas. In: CUNHA, J. M. P. da (Org.). Novas Metrópoles Paulistas: população, vulnerabilidade e segregação. 1 ed. Campinas: UNICAMP, 2006, v. , p. 337-363. Disponível em: 
http://www.nepo.unicamp.br/textos/publicacoes/livros/vulnerabilidade/arquuivos/arquui vos/vulnerab_cap_12_pgs_337_364.pdf

CUNHA, J. M. P. da; BAENINGER, R. Las migraciones internas en el Brasil Contemporáneo. Notas de Población, CEPAL/CELADE, Año XXXII, n. 82, 2007.

CUNHA, J. M. P. da; STOCO, S.; DOTA, E. M.; NEGREIROS, R.; MIRANDA, Z. A. I. de. A mobilidade pendular na Macrometrópole Paulista: diferenciação e complementaridade socioespecial. Cadernos da Metrópole. São Paulo: v.15, n.30, 2013. Disponível em:

http://www.cadernosmetropole.net/component/content/article/31/50-270

DOTA, E. M. Migração na RM de Campinas: produção do espaço urbano e impactos sociais. Dissertação (mestrado em Demografia) Campinas: IFCH-UNICAMP, 2011. Disponível em: http://www.bibliotecadigital.unicamp.br/document/?code=000785364 DOTA, E. M. Desigualdades e migração: como elas se inter-relacionam no momento atual? Boletim Campineiro de Geografia. Campinas: V.2, n.1, 2012. Disponível em: http://agbcampinas.com.br/bcg/index.php/boletim-campineiro/article/view/35

DOTA, E. M.; FREY, H. Dinâmica migratória nas regiões metropolitanas paulistas: o que revelam os dados? In: Anais do XVIII Encontro Nacional de Estudos Populacionais. Águas de Lindóia/SP, 2012. Disponível em:

http://www.abep.nepo.unicamp.br/xviii/anais/files/ST24[293]ABEP2012.pdf

DOTA, E. M. Mobilidade residencial intrametropolitana na RM de Campinas: uma abordagem a partir da distribuição espacial dos migrantes. Tese (doutorado em Demografia) Campinas: IFCH-UNICAMP, 2015. Disponível em: http://www.bibliotecadigital.unicamp.br/document/?code=000951871\&opt=4 FREY. H.; DOTA, E. M. O Censo de 2010 e as Primeiras Leituras Sobre a Mobilidade Espacial da População na Região Metropolitana de Campinas. Revista Mediações. Londrina: $\quad$ v.18, $2013.1, \quad$ Disponível em: http://www.uel.br/revistas/uel/index.php/mediacoes/article/view/16456

HARVEY, D. Condição Pós-moderna. São Paulo: Loyola, 1992.

MARANDOLA JR., E. J. Habitar em risco: mobilidade e vulnerabilidade na experiência metropolitana. Tese (doutorado em Geografia). Instituto de Geociências, Campinas, 2008. Disponível em:

http://www.bibliotecadigital.unicamp.br/document/?code=vtls000439077\&opt=4

MOURA, R. A dimensão urbano-regional na metropolização contemporânea. EURE, vol. 38, n.115, set. de 2012. Disponível em:

Serv. Soc. \& Saúde, Campinas, SP v. 14, n. 2 (20), p. 157-172, jul./dez. 2015 ISSN 1676-6806 
http://www.scielo.cl/pdf/eure/v38n115/art01.pdf

OJIMA, R. Análise comparativa da dispersão urbana nas aglomerações urbanas brasileiras: elementos teóricos e metodológicos para o planejamento urbano e ambiental. Tese (doutorado em Demografia). IFCH-UNICAMP, 2007. Disponível em: http://www.bibliotecadigital.unicamp.br/document/?code=vtls000431427\&opt=4 OJIMA, R.; MARANDOLA JR, E. Mobilidade populacional e um novo significado para as cidades: dispersão urbana e reflexiva na dinâmica regional não metropolitana. Revista Brasileira de Estudos Urbanos e Regionais, v. 14, n. 2, 2013. Disponível em: http:// unuhospedagem.com.br/revista/rbeur/index.php/rbeur/article/view/4104 RODRIGUES, J. Qué definiciones, que teorías, qué fuentes y qué metodologías precisamos para el estudio de la migración interna en la actualidad. In: CUNHA, J. M. P. da (Org.) Mobilidade espacial da população: desafios teóricos e metodológicos para o seu estudo. Campinas: NEPO/UNICAMP, 2011.

RODRIGUES, J.; BUSSO, G. Migración interna y desarrollo en América Latina entre 1980 y 2005: Un estudio comparativo con perspectiva regional basado en siete países. CEPAL, Chile, 2009.

SANTOS, M. A natureza do espaço. São Paulo, SP: EDUSP, 1996.

SASSEN, S. As cidades na economia mundial. São Paulo, SP: Studio Nobel, 1998.

SINGER, P. I. Economia política e urbanização. 3ed. CEBRAP, Brasiliense, 1976.

SOBRINO, L. J. Migración urbana. La situación demográfica en México, CONAPO, México, 2010.

VILLAÇA, F. Espaço intra-urbano no Brasil. São Paulo: Fapesp/Lincoln Institute/Nobel, 1993. 
Serv. Soc. \& Saúde, Campinas, SP v. 14, n. 2 (20), p. 157-172, jul./dez. 2015 ISSN 1676-6806 